\title{
Atributos espaciais da desigualdade nas grandes cidades brasileiras: uma relação entre segregação e morfologia
}

Spatial attributes of inequality in large Brazilian cities: a relation between segregation and morphology

Patrick Zechin [l] Frederico Rosa Borges de Holanda [II]

\section{Resumo}

Ao fazer uma análise comparativa entre regiões concentradoras das famílias de menor e maior renda per capita em cinco grandes cidades brasileiras (Goiânia, Fortaleza, Brasília, Belo Horizonte e Curitiba) e suas características morfologias, este artigo busca contribuir para a interpretação de um fator não monetário ligado à produção da desigualdade socioeconômica nas grandes cidades brasileiras. 0 intuito é analisar a relação entre a morfologia e a localização concentrada dos grupos antípodas de renda familiar per capta. Para isso, utilizam-se, como metodologia de análise, tanto análises georreferenciadas quanto análises morfológicas. Além de apontar padrões espaciais de regiões específicas, destacam-se, como conclusões mais gerais, as relações de regiões morfológicas específicas e a respectiva capacidade de integração e circulação dos grupos nelas residentes.

Palavras-chave: desigualdade não monetária; segregação; morfologia; integração; padrões espaciais.

\begin{abstract}
Through a comparative analysis of regions concentrating families with very high and very low per capita incomes in five large Brazilian cities (Goiânia, Fortaleza, Brasília, Belo Horizonte and (uritiba) and their respective morphologic features, this article aims to contribute to the understanding of a non-monetary factor connected with socioeconomic inequality in large Brazilian cities. The aim is to analyze the relation between morphology and opposed per capita income clustering formations. In methodological terms, both georeferenced and morphologic analyses are used. Besides indicating spatial patterns of specific regions, the more general conclusions that emerge are the relations of specific morphological regions and the capacity for integration and circulation of the groups that reside in them.
\end{abstract}

Keywords: non-monetary inequality; segregation; morphology; integration; spatial patterns. 


\section{Introdução}

A desigualdade socioeconômica é uma das questões fundamentais no Brasil, de sorte que, a partir dos anos 1970, o fenômeno passa a ser estudado no Brasil com grande intensidade por meio de análises tanto qualitativas quanto quantitativas, buscando compreender as causas e os fatores que permitem sua reprodução. No mesmo sentido, diversas políticas públicas vêm sendo desenvolvidas em maior ou menor quantidade e em graus variados de eficácia com vistas a ampliar as fronteiras inclusivas e diminuir o fosso que separa as classes sociais no País. Contudo, há evidências, como afirmam, Medeiros et al. (2015) de que a desigualdade de renda, além de ser mais alta do que se imaginava, permaneceu estável entre 2006 e 2012, uma vez que, apesar do crescimento da renda, os mais ricos se apropriaram da maior parte do crescimento econômico no período. Disto, fica evidente que há mecanismo que permitem que as famílias mais ricas se apropriem de maneira mais eficaz dos recursos socialmente produzidos nas grandes cidades. Ampliar a compreensão de tais mecanismos é fundamental para uma sintonia mais fina de políticas públicas de combate à desigualdade, por exemplo.

Esses mecanismos formam um complexo arranjo de causas da persistência da desigualdade e que, aparentemente, ao dissociar o aumento da renda geral da sociedade da redução na desigualdade, indicam que seu estudo não pode se restringir apenas à dimensão da renda, uma vez que, conforme apontado por Arretche (2018), a desigualdade é também composta por dimensões não monetárias como, por exemplo, o acesso a serviços públicos ou a eliminação da barreira do analfabetismo.
Para além da dimensão da renda, os estudos acerca da desigualdade no Brasil, em regra, dão-se sobre aspectos ligados à raça, ao gênero, à transição rural-urbana, ao mercado de trabalho, à educação ou à habitação. Entretanto, há pouca investigação sobre uma dimensão essencialmente espacial da desigualdade. Dito de outra forma, pouco se discute sobre o impacto da morfologia das cidades, resultante de suas evoluções históricas particulares, na produção e reprodução da desigualdade.

Este artigo visa contribuir com o debate sobre, não apenas a desigualdade nas grandes cidades brasileiras, mas sua surpreendente persistência, ao apontar a morfologia urbana como um fator a ser considerado, tanto na agenda de pesquisas sobre a desigualdade quanto na formulação de políticas urbanas referentes ao tema. 0 interesse nos fatores da morfologia urbana que podem afetar a desigualdade indica a importância de questões como localização de cada grupo dentro da estrutura urbana, capacidade potencial de deslocamento e acesso desigual ao conjunto de recursos socialmente produzidos, cujos significados dependem fortemente do lugar em que os indivíduos (re)produzem seus modos de vida na cidade e não apenas no diapasão da distribuição de renda.

Argumentamos que a desigualdade pode não ter sido reduzida, entre outros diversos fatores, devido à diferença de capacidade potencial de apropriação dos recursos socialmente produzidos na cidade, decorrente da desigualdade de atributos espaciais relacionados à capacidade global e local de as famílias acessarem o conjunto de recursos da cidade (serviços especializados, lazer, cultura, estoques de empregos melhor remunerados, etc.), devido à morfologia da região de 
concentração das famílias mais ricas e das famílias mais pobres e à relação entre essas regiões e o restante da cidade.

Podemos imaginar, de forma bastante empírica, que as cidades podem ser abertas ou fechadas em quanto à capacidade de seus habitantes de acessar, ocupar e usar a cidade no intuito de satisfazer suas necessidades objetivas e (re)produzir suas condições de vida. Para alguns, a cidade é onde acontece a vida social, econômica e política, onde o conhecimento e a cultura são criados e compartilhados; para muitos outros, a cidade é o lugar da exclusão e marginalização, ao lhes negar todas, ou quase todas, essas oportunidades, criando bolsões permanentes de famílias pobres.

As cidades brasileiras conhecem ambas as realidades. Nossa desigualdade é estrutural e é reproduzida desde o período colonial ancorado da escravidão. Ao final desta, e com o início de uma vida urbaniza gradativamente mais intensa, a desigualdade dar-se-á nas cidades, para utilizar a imagem elaborada por Gilberto Freyre, entre aqueles poucos moradores dos sobrados e os muitos que moram nos mocambos.

Este artigo se debruçará sobre uma dimensão específica e não monetária, a morfológica, relacionada com a integração interpartes das regiões de concentração das famílias de maior e menor renda per capita e com 0 papel que algumas rotas globais de movimento desempenham na capacidade potencial das diferentes classes sociais de acessarem a cidade. Dito de outra forma, queremos investigar como a morfologia urbana impacta os processos de (re)produção social por vezes de forma independente dos processos econômicos tradicionalmente estudados na formação das localizações.
No Brasil, as famílias de menor renda per capita, quase invariavelmente, encontram-se nas franjas das cidades em uma condição de segregação marcada pelo alijamento dos espaços de maior vitalidade urbana, que concentram oportunidades, dinâmicas e características que acabamos por associar, geralmente, ao atrativo da vida urbana. A questão é que esse grupo não se encontra uniformemente distribuído pela periferia das grandes cidades, mas, antes, extremamente concentrado em determinadas localidades. Já o segundo grupo se encontra, também, extremamente concentrado - mais até que o grupo anterior - quase que invariavelmente orbitando o centro histórico das cidades na forma de um centro expandido, o que gera um padrão muito marcante e que faz com que as famílias mais ricas conheçam - mais do que as famílias mais pobres - maior dependência espacial, característica definidora da estruturação da sua sociabilidade e da reprodução social de suas condições de vida.

Nosso objetivo é analisar a relação existente entre a espacialização dos grupos de renda familiar antípodas e a morfologia de suas respectivas áreas de concentração em cinco grandes cidades brasileiras (Goiânia, Fortaleza, Belo Horizonte, Brasília e Curitiba, nesta ordem) elencadas, pelo relatório State of the World's Cities 2010/2011 da ONU-Habitat, como as cidades mais desiguais do Brasil. A análise dar-se-á por meio da comparação da espacialização de dados censitários (Censo, 2010) referentes à renda com os atributos morfológicos das cidades estudadas. Além disso, discutimos as implicações da relação entre as localizações de concentração das famílias com menor e maior renda per capita e seus atributos 
morfológicos com a capacidade desses grupos de se locomoverem de seus locais de moradia para o restante da cidade.

Ao comparar a localização da renda com a morfologia da localidade de concentração dos grupos, inferimos que a maior ou a menor capacidade de se apropriar do conjunto de recursos existente na cidade está relacionada com a estrutura espacial das regiões de concentração. Isso parece ser mais perceptível para o grupo de maior renda.

Este artigo terá quatro partes, além desta introdução e de uma parte reservada às considerações finais. No segmento a seguir, abordaremos as escolhas metodológicas utilizadas nas análises que serão efetuadas. 0 objetivo é esclarecer a escolha de determinados atributos morfológicos e a análise comparativa com a renda.

Logo depois, trataremos do conceito de desigualdade e sua ligação com o conceito de segregação residencial, abordando a importância do tema para os estudos urbanos. Além disso, faremos um breve levantamento bibliográfico a respeito de como a desigualdade e a segregação residencial têm sido interpretadas, a fim de encontrar a motivação para o estudo morfológico.

Em seguida, com base nos dados do Censo de 2010 e nas bases cartográficas vetoriais das cidades estudadas, abordaremos a relação entre a espacialização dos grupos antípodas de renda familiar per capita e os atributos morfológicos das localidades de concentração. 0 objetivo é compreender a espacialização concentrada dos dois grupos como fator ou circunstância da estrutura espacial das respectivas localidades. Por fim, traremos considerações finais também com o intuito de apontar questões para reflexões e investigações futuras.

\section{Aspectos procedimentais}

Inicialmente, esclarecemos a escolha do critério de renda para elaborar a baliza da discussão da relação de atributos morfológicos na condição de desigualdade entre os dois grupos antípodas de renda familiar per capita, uma vez que a morfologia não é uma dimensão monetária. Segundo Arretche (2018), a centralidade da renda nos estudos comparativos sobre o fenômeno da desigualdade está mais ligada a uma disponibilidade maior desse tipo de dado do que ser a renda a única dimensão relevante para seu estudo, e, de fato, há críticas muito pertinentes relativas ao peso dado ao fator renda na abordagem do tema da desigualdade.

Contudo, para além da maior disponibilidade de dados relativos à renda, neste artigo, a escolha desse critério é devido a dois fatores. 0 primeiro diz respeito à abundância de sólidas evidências empíricas acerca das relações recíprocas entre renda e região de moradia, embora esta não seja uma relação necessária, como a presença de favelas na zona sul carioca atesta. 0 segundo está relacionado com a utilização do relatório elaborado pela UN-Habitat (2012), mencionado anteriormente. Este ranqueia as cidades mais desiguais dentro do conjunto dos países pobres ou em desenvolvimento, com base na comparação da desigualdade de renda medida pelo coeficiente de $\mathrm{Gi}$ ni. 0 relatório de todas as cidades da amostra apresenta um grupo de cinco cidades brasileiras (Goiânia, Fortaleza, Belo Horizonte, Brasília e Curitiba, nessa ordem) que aparecem, após 
um pequeno grupo de cidades sul-africanas, como aquelas mais desiguais do mundo, apresentando um coeficiente de Gini variando entre 0,65 para Goiânia e 0,59 para Curitiba.

Entretanto, ainda que a desigualdade captada pelo índice de Gini seja o ponto de partida, recorremos a outras ferramentas de análise, uma vez que o uso desse índice sofre de algumas desvantagens como, por exemplo, (1) a falha ao capturar a proporção da população de uma cidade (nesse caso) que é pobre ou rica; e (2) a incapacidade de medir dimensões não econômicas de uma dada região. Por isso, lançamos mão da Análise Exploratória de Dados Espaciais (Aede) conhecida como "autocorrelação espacial", que é a correlação ou similaridade de valores geralmente próximos em um conjunto de dados.

Para dados espaciais, a autocorrelação é esperada, quando valores medidos de forma próxima no espaço são mais similares que valores medidos de forma distante um do outro. Uma das técnicas mais utilizadas no estudo de fenômenos espaciais é aquela que permite identificar a estrutura de correlação espacial que melhor represente o padrão de distribuição dos dados analisados. Enquadra-se, nessa categoria, o Índice Global de Moran, que avalia a dependência espacial, ou seja, a covariação de propriedades dentro do espaço, e suas características podem estar relacionadas tanto positiva quanto negativamente e permitirão perceber a desigualdade entre diferentes regiões, o que, segundo Villaça (2001), explica melhor a importância da estrutura urbana e de suas articulações com os processos sociais fundamentais.

A outra ferramenta da qual lançamos mão para medir a relação da forma urbana nos processos de reprodução social é a Sintaxe Espacial (SE). A Teoria da Lógica Social do Espaço, como também é conhecida, segundo Holanda (2002), é uma teoria do campo da arquitetura e do urbanismo que relaciona (1) a configuração edilícia ou urbana em qualquer escala, ao considerar o sistema de barreiras e permeabilidades para o movimento e para as transparências e opacidades à visão; e (2) um sistema de encontro, esquivanças e estruturação social. A teoria, desenvolvida em suas linhas gerais por Hillier e Hanson (2003), implica um método definidor de um número de categorias analíticas nos campos do espaço e dos encontros e esquivanças e de como relacioná-las. A SE consiste, basicamente, na descrição da estrutura relativa à morfologia urbana entendida como um sistema de espaços livres públicos (não edificados), representados através de dois sistemas: o sistema de espaços convexos e o de linhas axiais (eixos), sendo este último derivado do menor número de linhas que se cruzam, atravessando todos os espaços convexos do sistema urbano.

Ambos os sistemas (axial e espaços convexos) não levam diretamente em consideração relações geométricas ou métricas, mas, antes, topológicas, ${ }^{1}$ na medida em que se transforma o conjunto de espaços em um sistema de ligações no qual o conjunto de interseções das linhas axiais ${ }^{2}$ é representado matricialmente. Essa matriz representa o conjunto de conexões de cada linha com todas as outras linhas do sistema. A informação de saída, resultado da matriz, é um conjunto de linhas cujas cores vão do azul escuro (representando as linhas menos integradas) até 0 vermelho (representando as linhas mais integradas do sistema). 
Para a SE, as propriedades de visibilidade e acessibilidade são dominantes na forma como o movimento das pessoas que se deslocam a pé se processa no espaço, assumindo a estrutura urbana a função de natureza social capaz de organizar padrões do movimento e intensidade de uso dos espaços.

Outro desenvolvimento teórico e ferramental ligado ao campo investigativo da SE foi apresentado por Turner (2000) e é chamado de análise angular do espaço. Esse método se apropria de três ideias fundamentais: (1) um indivíduo, ao se deslocar entre dois pontos, tenderá a fazê-lo com o menor número de voltas possível - ao invés de se utilizar do caminho mais curto, como o senso comum poderia assumir inicialmente; (2) qualquer ponto do sistema urbano pode ser considerado o início ou o fim de uma jornada; e (3) uma jornada - de qualquer ponto a outro - é igualmente tão provável a qualquer outra. Assim, o conceito mais importante para a análise angular é o do caminho angular mínimo entre dois pontos quaisquer do sistema urbano.

Ao indicar o potencial de um determinado eixo ser atravessado para a realização de um percurso qualquer, levando em consideração o caminho topológico mais curto (ou seja, com menor número de inflexões), a análise angular identifica o conjunto de vias que estruturam as principais rotas globais de movimento. Estas, de uma forma geral, formam uma estrutura de longas vias conectadas em seus extremos em ângulos abertos, formando uma estrutura muito ordenada, que cria conexão interpartes tanto das porções contínuas quanto descontínuas do tecido urbano.

No que se refere à renda, os grupos analisados são aqueles definidos pelos critérios estabelecidos pelo Censo do IBGE (2010). 0 primeiro é o conjunto de domicílios particulares com rendimento nominal mensal per capita entre 1/8 e 1/4 de salário mínimo (SM) e o segundo é o conjunto de domicílios com rendimento nominal mensal per capita de mais de 10 SM. No Quadro 1, temos os números gerais do universo de domicílios distribuídos por faixa de renda, mas, paralelamente, adicionamos o número dos domicílios considerados de renda média pelo Censo por entender que esse número dá uma ideia geral da escala dos grupos estudados.

No Quadro 2, encontramos os níveis analíticos que exploraremos neste trabalho: os padrões espaciais e as categorias socioeconômicas.

Por informação, referimo-nos ao que a variável comunica e que é transformado por meio de técnicas computacionais em dados numéricos e mapas, que permitem a pronta apreensão das informações contidas na abstração do mapa axial, por exemplo.

Por abrangência, apontamos o recorte espacial da análise. Nesse sentido: (1) local refere-se a partes do sistema urbano tomados separadamente; (2) global diz respeito ao sistema tomado como um todo e por análise quantitativa, entendendo que a avaliação se dará mediante aparato estatístico. 
Quadro 1 - Número de domicílios por faixa de renda

\begin{tabular}{|l|c|c|c|c|}
\hline \multicolumn{1}{|c|}{ Município } & $\begin{array}{c}\text { Número } \\
\text { de domicílios } \\
\text { com baixa renda }\end{array}$ & $\begin{array}{c}\text { Número } \\
\text { de domicílios } \\
\text { com alta renda }\end{array}$ & $\begin{array}{c}\text { Número } \\
\text { de domicílios } \\
\text { com média renda }\end{array}$ & $\begin{array}{c}\text { Número total } \\
\text { de domicílios }\end{array}$ \\
\hline Goiânia & 8.359 & 13.236 & 400.577 & 422.172 \\
Fortaleza & 55.324 & 13.694 & 641.048 & 710.066 \\
Belo Horizonte & 17.289 & 35.829 & 672.957 & 726.075 \\
Curitiba & 23.781 & 58.827 & 691.413 & 774.021 \\
\hline
\end{tabular}

Fonte: elaboração própria, a partir dos dados do censo IBGE (2010).

\section{Quadro 2 - Níveis analíticos}

\begin{tabular}{|c|c|c|c|c|}
\hline ID & Variável & Informação & Abrangência & Análise \\
\hline \multicolumn{5}{|c|}{ Socioeconômicas gerais } \\
\hline 1 & Formação de cluster & Valor total & Local/Global & Quantitativa \\
\hline \multicolumn{5}{|c|}{ Padrões espaciais } \\
\hline 2 & Integração & Valor total & Local & Quantitativa \\
\hline 3 & Choice & Valor total & Global & Quantitativa \\
\hline
\end{tabular}

Fonte: elaboração própria a partir de Holanda (2002). 


\section{Padrão da desigualdade brasileira: debates}

Não há dúvidas acerca da complexidade, multiplicidade e vastidão do tema da desigualdade e sua investigação, que leva à necessidade de sucessivos recortes, a fim de conseguir privilegiar ângulos específicos das fontes e consequências da desigualdade em nossa sociedade. Na impossibilidade de discutir todos os recortes possíveis sobre 0 assunto, tentaremos chamar a atenção principalmente para alguns aspectos atidos à renitência de nossa desigualdade estrutural.

Segundo Reis (2000), embora a sobrevivência material de grande contingente populacional seja um problema dramaticamente concreto, não há questionamentos de que é a desigualdade e não necessariamente a pobreza 0 aspecto distintivo da sociedade brasileira. Também há poucas dúvidas de que as desvantagens não materiais perpetuam e aprofundam nosso padrão de desigualdade na distribuição de bens e serviços. 0 Brasil não é um país pobre, mas, antes, um país com um grande contingente de pobres e, portanto, com um elevado nível de pobreza, cujo determinante parece estar relacionado com aspectos estruturais de sua desigualdade, como, por exemplo, a questão racial - alvo de vários estudos -, mas também a questão da configuração física das cidades, como procuramos demonstrar neste trabalho.

A história do Brasil mostra uma incrível constância dos padrões de desigualdade, que parece imune a políticas econômicas e mesmo ao crescimento de renda. Barros et al. (2011) mostram que a pobreza no Brasil não pode ser associada prioritariamente à escassez, absoluta ou relativa, de recursos, mas sim ao elevado grau de desigualdade na distribuição de recursos. Mostram, também, a estabilidade surpreendente da desigualdade desde os anos 1970, apesar de o País, em alguns momentos, ter conseguido fazer com que o número de pobres declinasse, como nos períodos do milagre econômico, dos planos Cruzado e Real.

Já Medeiros, Guimarães e Castro (2015) apontam que a desigualdade total não caiu entre 2006 e 2012. Embora tenham ocorrido mudanças na base de distribuição, a concentração no topo permaneceu praticamente constante, devido à capacidade dos ricos em se apropriarem da riqueza socialmente produzida, o que determinou uma tendência de estabilidade e não de queda na desigualdade, uma vez que os dados tributários analisados indicam que a divergência no comportamento da desigualdade é determinada pelo comportamento da renda dos ricos.

Uma característica estrutural de nossa desigualdade é que ela parece ser relativamente imune ao aumento geral da renda. Medeiros, Guimarães e Castro (ibid.) exemplificam que, por exemplo, entre 2006 e 2009, a pequena elite formada pelo $1 \%$ mais rico da população apropriou-se de uma fração 117 vezes maior do crescimento do que as pessoas na metade mais pobre do País. Já, entre 2009 e 2012, houve uma tendência geral de redução da desigualdade, porém o aumento nas parcelas apropriadas do crescimento em todos os estratos sociais é bastante uniforme. Segundo a pesquisa, apenas cerca de um décimo de todo o crescimento foi para as mãos da população mais pobre do País, e cerca de metade do crescimento coube aos $5 \%$ mais rico, o que tem efeitos significantes sobre o nível de desigualdade, já que o dado 
importante não é tanto a mudança no nível da renda dos mais pobres em um dado período histórico, mas, antes, a fração do crescimento total da economia da qual eles se apropriam.

Desse modo, percebemos que, embora a diferença de renda seja um atributo importante da desigualdade total, ela pode não ser o elemento preponderante, mas mais um entre vários fatores causais da desigualdade. As duas referências acima levam em consideração a renda e enfatizam a persistência da desigualdade ao longo de mais de quarenta anos, quase independentemente de ciclos de crescimento ou distribuição de renda. Daí podemos inferir que, embora a renda seja a face mais visível e que impacta as condições concretas da subsistência material dos indivíduos, é preciso avançar também na investigação de outros atributos da dinâmica da desigualdade que permitem que os ricos se apropriem tão eficientemente de uma grande parcela da riqueza socialmente produzida.

De acordo com Arretche (2018), o acesso a serviços afeta a renda real dos indivíduos e, mais, a depender dos regimes de política social, esta pode produzir superposição de vantagens/desvantagens sobre as mesmas categorias de indivíduos. A partir dessa ideia, a autora indica que a desigualdade econômica seria mais acentuada do que a desigualdade de renda, o que só é verificável com a inclusão de dimensões não monetárias no conceito de desigualdade.

Normalmente, essas dimensões não monetárias englobam consumo material, qualidade habitacional, saúde, mercado de trabalho, lazer, qualidade de interações sociais, qualidade ambiental, direitos políticos e liberdade de expressão. Como todas elas guardam relação com o espaço urbano concreto, cabe indagar sobre as condições da capacidade de acesso propriamente dito e sua desigualdade, ou seja, de que forma a cidade, enquanto um sistema de barreiras e permeabilidades ao movimento, condiciona, ainda que potencialmente, o acesso dos grupos aos recursos da cidade. 0 sistema de acessos é, ele mesmo, um atributo não monetário componente da desigualdade.

Entendemos como uma lacuna nos estudos acerca da desigualdade, ao menos no Brasil, a ausência de debate sobre a estrutura física das cidades, uma vez que evolução delas implica processos que culminam em estruturas caracterizadas pela fragmentação, dispersão e segregação.

0 relatório da UN-Habitat (2012) não diferencia a desigualdade de renda de outra não monetária, mas seus dados procuram demonstrar a relação entre elas e o impacto que ambas têm sobre as populações. Da leitura do relatório, depreendemos que grandes parcelas das sociedades são frequentemente excluídas, sobre o pretexto de atributos pré-determinados, como gênero, idade, etnia, lugar onde moram, gerando a expressão "urbano dividido", para explicar esse estado de coisas. A expressão faz referência, não apenas a uma comunidade rompida por desigualdades socioeconômicas, mas também a comunidades com pouca inclusão política e cultural.

Fica evidente que o relatório não considera a desigualdade nas cidades como sendo apenas de renda ou consumo, mas também aquela que se reflete em padrões entrincheirados no desenvolvimento e propriedade do próprio espaço físico, como as decorrentes da separação mais ou menos radical entre ricos e pobres, fruto também de uma ampla combinação de 
fatores durante o processo de desenvolvimento urbano, governança e exclusão institucionalizada de grupos específicos.

Combinados, o apartamento físico e social entre áreas ricas e pobres, criam uma dinâmica social que pode ser entendida como uma espécie de armadilha espacial que afeta os mais pobres em relação a (1) restrição a emprego; (2) piora nas condições de vida; (3) marginalização; (4) falta de interação social; (5) alta incidência de crimes; e (6) disparidade de gêneros.

Ainda que a ideia de um "urbano dividido", desenvolvida pelo relatório, seja, de certa maneira, corroborada empiricamente pela disparidade nas paisagens urbanas de centro e periferia, precisamos questionar se a desigualdade entre as duas paisagens (centro e periferia) justifica o discurso da divisão entre uma cidade dos ricos e uma cidade dos pobres como se fossem duas realidades separadas.

Falar em uma cidade dos ricos e uma dos pobres ou uma cidade da ordem e outra do caos se sustenta apenas enquanto nos atemos aos aspectos aparentes da realidade. Para ser compreendida, a produção do espaço urbano necessita ser discutida, tendo em mente que ambas as regiões são resultado da mesma relação de produção que faz com que o espaço urbano produzido sob a égide do valor de troca se imponha ao uso social da cidade.

É a produção do espaço urbano favorecida por relações de mercado que promovem um mercado de terras pequeno e regulado, em regra, nas regiões do centro e do centro expandido, e outro precário, quando não ilegal (Maricato, 2003). Neste segundo, a terra está submetida a processos de loteamentos ilegais, ocupação e autoconstrução. Essa faceta da desigualdade não tem a ver apenas com a renda, mas também com certas relações políticas e sociais típicas de nossa sociedade e engendra outro processo que não se resume à desigualdade, mas, nas cidades brasileiras, está profundamente ligado a ela, que é a segregação espacial, a ponto de ser, ao mesmo tempo, uma das faces mais importantes da desigualdade social e promotora dela.

0 conceito de segregação está ligado aos estudos pioneiros dos sociólogos da Escola de Chicago, que estudaram a cidade, então em pleno crescimento, com uma população formada em grande medida por imigrantes. Segundo esses estudos, os diferentes graus de interação e de assimilação dos imigrantes e o grau de segregação dos negros levaram à formação de diferentes "áreas sociais" (Vasconcelos, 2013). A partir daí o conceito de segregação foi transferido para outras realidades sociais e utilizado para analisar as desigualdades socioeconômicas. No Brasil, os dois conceitos, desigualdade e segregação, são bastante utilizados para examinar o comportamento da cidade brasileira na análise e na denúncia da condição de exclusão social e de extrema carência material. De um modo geral, a segregação dá forma de desigualdades sociais às desigualdades espaciais.

0 fundamental na abordagem que imbrica desigualdade e segregação na cidade brasileira é que ela articule o conceito de segregação ao restante da estrutura urbana e da totalidade social (Villaça, 2001). Embora nossas cidades sejam bastante desiguais em seu conjunto, a segregação não ocorre na forma de uma oposição entre centro e periferia, com os ricos no centro e os pobres uniformemente distribuídos na periferia, mas concentra-se mais em algumas regiões do que em 
outras. Esse comportamento reflete, por certo, a desigualdade, uma vez que aquela é a mais importante manifestação espacial desta (Maricato, 2003), mas também é fruto de dinâmicas urbanas próprias, explicadas por processos próprios de desenvolvimento ao longo da história.

Tais processos, no caso das cidades brasileiras, gera, segundo Villaça (2001), regiões homogêneas, e o estudo dessas regiões segregadas consistem em uma excelente forma de interpretar a desigualdade em nossas cidades, porque é a forma de exclusão espacial e de dominação que tem uma dimensão espacial. $A$ análise da desigualdade elaborada por Villaça (ibid.) a partir da sua justaposição com a segregação, enquanto fator explicativo de primeira ordem, é ancorada no entendimento do processo de dominação social pela desigual distribuição de vantagens e desvantagens do espaço socialmente produzido.

Estas dizem respeito, principalmente, à manipulação, pela classe dominante, dos tempos gastos nos deslocamentos espaciais dos habitantes da cidade. A otimização dos tempos de deslocamento dos moradores é o mais importante fator explicativo da organização do espaço urbano (ibid.), com o grupo dos mais ricos otimizando seu próprio tempo de deslocamento, ao produzir o seu espaço de reprodução social de sua forma de vida.

A argumentação de Villaça vai ao ponto central de importantes mecanismos da (re)produção da desigualdade nas cidades brasileira, mas não dá a devida importância aos aspectos morfológicos daquilo que ele chama de estrutura urbana, deixando uma lacuna explicativa. Essa lacuna pode ser preenchida, a partir de um estudo analítico da morfologia das cidades com instrumento teórico, metodológico e ferramental próprio, contribuindo para 0 avanço na explicação da relação dos espaços segregados com a estrutura urbana e os deslocamentos espaciais.

Chamamos aqui a atenção para o polêmico ponto do determinismo arquitetônico. Decerto não queremos sugerir uma relação biunívoca entre arquitetura e comportamentos sociais, como postulado algumas vezes por pioneiros do Movimento Moderno, mas entendemos que falar de congruência não é falar em determinação entre arquitetura e comportamento, mas reconhecer que a arquitetura - tanto urbana quanto edilícia - cria, sim, um campo de possibilidades e um campo de restrições, possibilidades que podem - ou não - ser exploradas e/ou superadas (Holanda, 2013).

Do que foi exposto até aqui, é possível resumir as hipóteses e as questões que pretendemos investigar nos seguintes pontos: (1) é possível dizer que nas cidades estudadas há um processo de formação de cluster (região), em que um grupo de renda exclua o outro, formando dois polos muito distintos entre si e com o restante da cidade?; (2) existe um padrão espacial ao qual podemos associar os dois clusters de renda familiar per capita?; (3) qual a relação entre as regiões de concentração dos mais ricos e dos mais pobres com a estrutura urbana e os deslocamentos espaciais?

\section{Medindo a segregação nas cinco cidades mais desiguais do país}

Uma interpretação sobre a desigualdade depende muito fortemente da métrica utilizada 
para medi-la. Tradicionalmente, o método estatístico mais utilizado para verificar a concentração espacial de um grupo, nas diferentes regiões da cidade, é o índice de dissimilaridade (D), apresentado por Duncan e Duncan (1955). Entretanto, há críticas contundentes aos cálculos de índices puros relativos à dissimilaridade, argumentando (Sabatini e Sierralta, 2006) que o índice de dissimilaridade apresenta um problema metodológico, ao dar pequena atenção ao fato de que a segregação tem escalas distintas em uma mesma cidade.

No que diz respeito ao nível analítico referente aos dados socioeconômicos gerais, nosso interesse, ao processarmos os dados disponibilizados pelo Censo de 2010, é saber quão concentrado ou disperso espacialmente são os atributos de riqueza ou pobreza no conjunto das áreas urbanas identificadas com os setores censitários delimitados pelo IBGE. Espacializar a distribuição dos dois grupos de renda opostos dará a medida de como a segregação urbana se apresenta nas cidades analisadas, na forma de regiões homogêneas e segregadas entre si. A ferramenta analítica da autocorrelação espacial tem como saída a determinação de clusters espaciais, quando a autocorrelação espacial for positiva, e indicar dependência espacial (nesse caso renda). Com o intuito de localizar clusters indicadores da segregação dos grupos de renda, vamos utilizar um método global e um local, que sumarizam padrões para toda a área de estudo.

Para a autocorrelação espacial global, os dados disponíveis são explorados de forma generalizada, caracterizando a associação espacial de uma região através de uma única medida, ou seja, um indicador global que viabiliza a medição do grau de interdependência espacial entre as variáveis, além de determinar a força e a natureza de tal relação. Segundo Almeida (2009), em estudos de análises estatísticas sobre a pobreza, os resultados de métodos globais, como o I de Moran, implicam, em geral, que as regiões consideradas pobres estão propensas a serem circundadas por regiões vizinhas igualmente pobres para valores de I de Moran, tendendo a 1.0 contrário também é verdadeiro para quando o resultado do I de Moran tende a 1, o resultado é que regiões não pobres estão propensas a serem circundadas por regiões igualmente não pobres. De forma análoga, as regiões pobres estarão próximas de regiões não pobres para o caso de valor de I de Moran, tendendo a -1, e o contrário também é verdadeiro. Os valores esperados para o I de Moran global estão agrupados no Quadro 3.

Todavia, apenas a medida global não é completamente confiável porque ela, por si só, pode ocultar o padrão local de associação espacial linear, como no caso de um I de Moran insignificante, que pode levar à conclusão de autocorrelação com a mesma característica. Torna-se importante complementar a análise com a busca de padrões locais de associação linear, que é alcançada com a medida de autocorrelação espacial local.

Percebemos, a partir da análise do I de Moran local, que as cidades estudadas tendem a formar clusters referentes aos dados apresentados pelo quadro sobre o valor do rendimento nominal médio das pessoas responsáveis por domicílios particulares permanentes, ou seja, há formação de clusters espaciais para o percentual de pessoas muito pobres e muito ricas em todos os casos estudados, como vemos na Figura 1. 
Quadro 3 - I de Moran Global para as cidades estudadas.

\begin{tabular}{|l|c|}
\hline \multicolumn{1}{|c|}{ Município } & I de Moran \\
\hline Goiânia & 0,169087 \\
Fortaleza & 0,528401 \\
Belo Horizonte & 0,500704 \\
Brasília & 0,388922 \\
Curitiba & 0,760274 \\
\hline
\end{tabular}

Fonte: Elaboração própria, a partir dos dados do Censo IBGE (2010).

0 cluster do grupo de famílias com maior renda per capita toma a forma de uma espécie de casulo em volta do ponto adotado como central na cidade, enquanto o cluster referente ao grupo das famílias com menor renda per capita não repete o mesmo comportamento, apresentando-se, por vezes, de forma não contínua no tecido urbano. Esse comportamento espacial indica, como esperado, uma ligação mais estreita do grupo mais rico com o seu espaço urbano. Fica evidente que a expansão da classe mais rica se dá em volta do centro histórico sem se afastar muito dele, uma vez que essa classe constrói o espaço urbano para a reprodução social de seu modo de vida, conforme demonstrado por Villaça (2001). A segregação das famílias mais ricas é esperada, na medida que esse grupo tende a produzir sua própria área de reprodução social, ao controlar o uso e a ocupação do solo. Os dados demonstram a existência de um padrão de segregação que molda a separação mais completa possível dos extremos do espectro econômico.

Desses dados, é possível perceber o grande isolamento dos grupos de renda antípodas. Estatisticamente, é muito baixa a probabilidade de famílias da Área de Menor Rendimento
(AMenR) serem vizinhas de alguma família pertencente da Área de Maior Rendimento (AMR). Três pontos chamam a atenção e ficam muito evidentes: (1) a falta de diversificação social em certas regiões da periferia das cidades; (2) a concentração das famílias mais ricas em regiões muito pequenas das cidades; e (3) grupos de renda intermediária com maior interação com os demais, de modo que formam uma espécie de área de transição entre as duas regiões de não interação.

Se, por um lado, é preciso evidenciar que, fora dos extremos, não há tendência de segregação residencial, ou seja, as cidades analisadas contam com suas classes médias e baixas (mas não tão baixas) razoavelmente bem distribuídas por toda a área do município; por outro, é preciso investigar mais profundamente - o que foge do escopo deste artigo - se as famílias muito pobres não começam a sofrer uma espécie de "efeito gueto" como resultado da consolidação, ao longo de muitas décadas, de seus lugares de assentamento.

Os mapas da Figura 1 nos ajudarão a interpretar melhor um componente não monetário na formação de regiões ocupadas quase exclusivamente pelos grupos antípodas. 
Figura 1 - I de Moran local para as cinco cidades estudadas
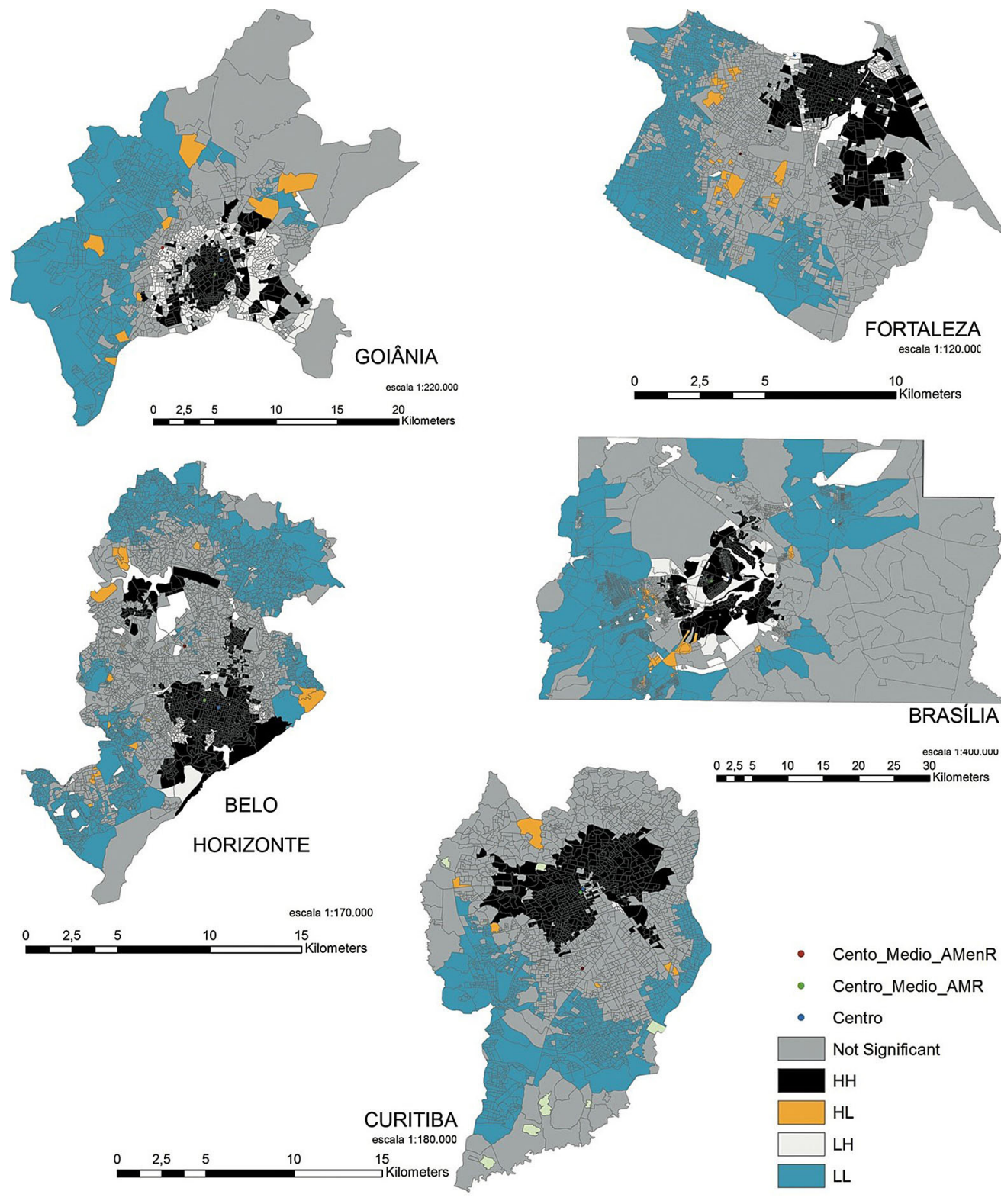

Kilometers

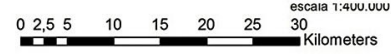

Fonte: elaboração própria, a partir dos dados do Censo IBGE (2010). 


\section{Análise morfológica da segregação socioeconômica}

A segregação espacial decorrente da desigualdade nas cidades brasileiras transfere para os espaços segregados o enorme desnível socioeconômico entre os mais ricos e os mais pobres. Contudo, conforme podemos perceber pela Figura 1, há muitas regiões em que essa clivagem socioespacial não é tão marcante, existindo áreas em que o processo de afastamento social no espaço se dá de forma mais matizada, ao contrário das regiões de dominância das classes antípodas.

Uma possível resposta para a pergunta acerca do porquê da existência de ao menos duas regiões particularmente segregadas varia, por um lado, de cidade para cidade, por conta de processos históricos, socioeconômicos e políticos particulares; mas, por outro lado, uma parte da resposta encontra-se atrelada à produção por parte das famílias de maior poder aquisitivo de um espaço próprio para a reprodução social de seu modo de vida. Para buscar o liame entre a produção social desse espaço e sua forma, partimos do princípio de que a arquitetura urbana é um sistema de barreiras e permeabilidades para o movimento de transparências e opacidades à visão, de cheios e vazios impregnados de práticas sociais (Holanda, 2013) e que os lugares produzidos no processo da evolução histórica de cada cidade estão ordenados em sistemas de contiguidades, continuidades, proximidades, separações, hierarquias, circunscrições. Tais sistemas implicam a organização de grupos de pessoas no espaço e no tempo, ou seja, quem está próximo ou não de quem, fazendo o quê, quando. Essas dimensões socioespaciais têm implicações quanto a estruturações, simetrias ou assimetrias sociais e estruturas de poder e influência.

Para Villaça (2001), o espaço urbano pode ser representado, em sínteses, por meio de suas estruturas fundamentais, como, por exemplo, o centro principal e as instâncias que revelam as forças fundamentais que determinam essa estrutura, quais sejam, as localizações das vias regionais e dos bairros residenciais. Buscamos entendê-las, em uma sintonia mais fina, percebendo-as como parte de um sistema de barreiras e permeabilidades para o movimento dos grupos. 0 movimento de pessoas é condição para a criação de vitalidade no espaço urbano e, segundo Hillier (1996, 2000) e Hillier et al. (1993), a criação do movimento está intrinsecamente ligada à configuração do próprio arranjo com as cidades explorando esse movimento para criar densidades e utilizando o espaço como criador de efeitos multiplicadores na relação entre movimento e encontro de pessoas. Esse efeito multiplicador do espaço é, na maioria das vezes, concentrado em certas regiões e não em outras e encontra rebatimento em circunstâncias, como a diferença do valor de troca das localidades nas diferentes regiões da cidade. 0 potencial para a criação do movimento a partir da própria morfologia pode ser aferido e comparado por meio de ferramentas analíticas próprias, e o resultado pode ser percebido na Figura 2.

Para a análise da categoria dos padrões espaciais, iremos nos utilizar da seguinte convenção: chamaremos de Área de Maior Rendimento (AMR) e Área de Menor Rendimento (AMenR) os clusters identificados na Figura 1 como sendo aqueles de concentração das famílias de maior renda per capita e as das famílias 
de menor renda per capita. Também nos referiremos ao Núcleo de Integração (NI), que é o conjunto de linhas pertencentes à banda cromática vermelha no mapa axial, isto é, os eixos mais integrados.

Na Figura 2, vemos os resultados da medição do atributo da integração das vias formadoras dos sistemas urbanos para um raio de análise global ${ }^{3}(\mathrm{Rn})$ de maneira que é possível perceber uma coincidência - grande, embora não total - do cluster da AMR com o chamado, na tradição da SE, de Núcleo de Integração; de forma paralela, a AmenR coincide com áreas de baixa integração global ao sistema.

0 que, contudo, à primeira vista, chama-nos a atenção são outros atributos morfológicos comuns às cidades estudadas: a descontinuidade, a malha esparsa e a redução da escala urbana das manchas para além do NI formado pelas linhas mais integradas (aquelas cuja cor tendem para o vermelho) do sistema. Esses atributos apontam para vazios urbanos que tanto podem ser devido a feições geográficas peculiares, como morros ou fundos de vale, quanto a glebas desocupadas à espera da valorização decorrente do investimento público em melhorias, forçado pela constante incorporação e parcelamento de novos estoques de terra, muitas vezes para além dos vazios formados por terras não parceladas.

Já a medida de integração permite que conheçamos melhor os componentes espaciais da segregação. Identificamos um conjunto de linhas na cor vermelha que indica o maior potencial de acessibilidade ou permeabilidade, indicando vários possíveis percursos que ali podem ser percorridos. Essas são mais facilmente alcançáveis a partir de qualquer outro ponto da cidade. Para as linhas menos integradas (pertencentes à banda cromática do azul), inverte-se a afirmação. Sem desconsiderar os fatores econômicos, políticos, sociais e culturais do desenvolvimento urbano de cada cidade, Hillier (2000) indica, na morfologia, a grande geradora de movimento espontâneo, o que tende, no NI, a formar a centralidade principal de qualquer cidade. Essa condição está atrelada a um pequeno conjunto de linhas com os maiores valores unitários de integração e um conjunto subsidiário de linhas ligadas a elas, formando uma malha urbana de "dois-passos" ou "três-passos". ${ }^{4}$

Os estudos no campo da SE identificam, nas condições do traçado local, o conjunto do centro dinâmico que tende a maximizar a acessibilidade local para aquelas poucas linhas mais integradas e seu sistema subsidiário. 0 sucesso dos centros dinâmicos, cheios de vida urbana, ou a forma básica de centralidade, requer tanto uma posição superior de integração global quanto uma morfologia local acessível e, assim, gerar as facilidades do centro através de um conjunto variado de rotas rápidas e fáceis, que também maximizam o acesso das famílias que moram na região ao complexo conjunto de recursos (estoques de empregos melhor remunerados, lazer, serviços especializados, educação, cultura, etc.), identificados com os centros históricos e a região do centro expandido.

Par Hillier (ibid.), há dois tipos de movimentos que geram centralidades dinâmicas: (1) o "movimento para" - essencialmente unidimensional e conhecido como movimento origem-destino e (2) "movimento em torno", ou seja, dentro de uma região e que relaciona todas as origens em todos os pontos da cidade e todos os destinos dentro daquela região, sendo essencialmente bidimensional, convexo na 
Figura 2 - Mapas axiais de integração global (Rn)

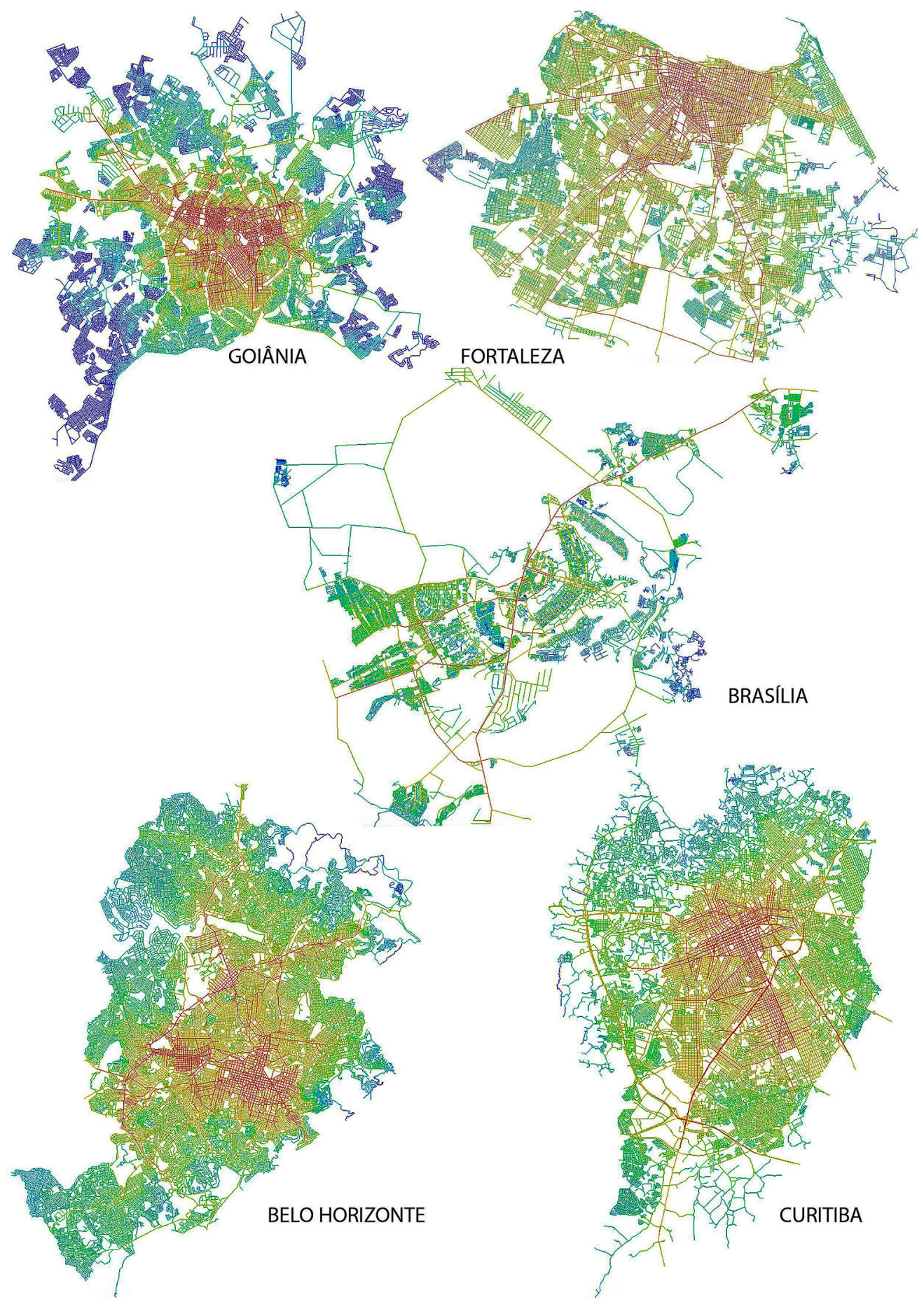

Fonte: elaboração própria, a partir dos dados do Censo IBGE (2010). 
forma e gerador de formas quase ortogonais de traçado. 0 primeiro tipo de movimento é pendular e é típico das famílias de menor renda per capita principalmente na condição de consumidores (Villaça, 2001), que se deslocam de suas casas para as compras, o serviço médico especializado, a escola, o lazer. Já o segundo tem o efeito de otimizar a integração métrica, a qual minimiza o comprimento das viagens de todos os pontos para os outros, dentro de uma área em geral pequena da cidade. É o movimento típico das famílias de maior renda per capita na (re)produção de seu espaço social.

As áreas da AMenR não são particularmente menos integradas do que outras partes das cidades, o que parece indicar, nesse caso, maior influência de condições políticas e econômicas de formação das periferias das grandes cidades brasileiras, embora todas elas tenham características morfológicas que as aproximem, como, por exemplo, as intensas fragmentação e dispersão. Já, no que se refere à AMR, o padrão é claro e pode indicar uma grande dependência espacial das famílias de maior renda per capita.

Verificamos a existência de padrões claros para Goiânia, Fortaleza, Belo Horizonte e Curitiba no que se refere à integração. Contudo, para Brasília, o padrão não se aplica, já que, para o Plano Piloto - região que comporta a quase totalidade da AMR -, há uma subversão da ideia de movimento nos moldes de como ele é entendido no âmbito da SE. No Plano Piloto, devido ao tombamento, a legislação determina os locais do comércio, e estes não mudam. Portanto, nem sempre a localização do comércio ou dos serviços estará associada com medidas sintáticas globais, à medida que o sistema cresce com o tempo e há, ainda, atributos locais (tais como tamanho de lote, existência ou não de pilotis, de garagens subterrâneas ou elevadores, ruas terminando em cul-de-sac, etc.), que influenciam fortemente a distribuição das classes sociais.

Outro aspecto a ser analisado é o das grandes vias estruturadoras dos sistemas urbanos, uma vez que estes funcionam como poderosos elementos de articulação das diversas regiões da cidade, unindo as localizações mais distantes às áreas mais densas e contínuas do tecido urbano. Para medir a estruturação linear do sistema e a força dessas vias em sua estruturação, utilizaremos uma medida sintática chamada choice, que calcula a frequência que um segmento é potencialmente selecionado para viagens entre todos os pares de origens e destinos, sob uma determinada definição de distância. Essa medida capta, segundo Hillier (2009), o movimento "através de" potencial de cada segmento, ou seja, seu potencial enquanto rota de todos os segmentos para todos os outros segmentos.

A medida de choice identifica, a partir da análise angular dos segmentos, a estrutura principal de rotas globais do sistema estudado, assumindo uma forma dual (1) uma rede em primeiro plano contendo um pequeno número de vias longas e bem-conectadas que são as rotas globais de movimento e (2) uma rede em segundo plano formado por um grande número de pequenas linhas que tendem a interceptar umas às outras e se conectarem em seus extremos, por meio de ângulos fechados, e a formar arranjos de importância local.

0 sistema de vias, em primeiro plano, indica um conjunto de rotas que se constituem potencialmente no conjunto dos caminhos de maior fluxo de movimento da cidade, que, no caso dos sistemas analisados na Figura 3, 
concentra-se, em grande medida, também na região de moradia das famílias de maior renda per capita e oferece a elas um conjunto de rotas privilegiadas ao restante da cidade.

Comparando os mapas resultantes da análise angular do espaço, medindo a variável choice para as cinco cidades estudadas, características distintivas das AMR ficam evidentes. Nelas encontramos a formação de conjunto denso e único de vias funcionando como rotas globais de movimento, que se cruzam em vários sentidos, formando uma rede em primeiro plano, que indica a formação de uma região concentrada localmente de rotas globais de movimento.

Nessa região, encontramos também um conjunto de segmentos formadores de uma rede de segundo plano muito localizado, funcionando como se fossem "vilas" bastante conectadas com o restante do sistema urbano, por meio da densa rede de vias globais. Esse padrão é esperado, segundo Hillier (2009), nos interstícios do arranjo denso de grandes vias globais de movimento e é formado por um grande número de pequenos segmentos com altos índices indicadores de potencial para o movimento "através de", apontando para a formação de importantes rotas locais de caminhos.

A partir do conjunto denso de vias globais de movimento que se cruzam, formando uma rede de rotas estruturadoras do tecido urbano, temos o prolongamento radial de algumas delas em direção às franjas da cidade.

0 padrão morfológico típico das cidades brasileiras é o do prolongamento radial de um conjunto pequeno de vias mais longas, estruturadoras, que partem do centro e que praticamente não se cruzam com outras de função semelhante, de modo a não formar uma rede de movimento intenso, análoga à da região central. 0 que vemos é a prevalência dos pequenos segmentos pertencentes à rede de segundo plano, também concentradores das moradias da região, ligados fracamente à pouco densa rede de primeiro plano. Praticamente não há rede de primeiro plano que ligue transversalmente as redes de segundo plano entre si, de modo a criar uma malha capaz de suportar o processo gerador de vitalidade nas localidades descrito anteriormente. No caso das AMenR, a escassez de grandes vias geradoras de movimento é ainda maior, o que potencialmente acarreta uma vitalidade de movimento ligada à formação de uma vida econômica local ainda maior.

Dessa forma, a elite ocupa um espaço que conjuga rotas locais com elevada acessibilidade às rotas globais, o que significa tanto grande facilidade de movimento dentro de seu espaço de moradia, produção, consumo e lazer, quanto facilidade para sair de seu local de fixação para atingir radialmente toda a cidade, utilizando-a como um sistema de recursos a sua disposição.

Podemos dizer, de forma sintética, em primeiro lugar, que, embora as cidades tenham processos próprios de evolução urbana ao longo de suas histórias, há a formação de padrões morfológicos que marcam as diferentes regiões formadoras de clusters de renda familiar antípoda no que se refere à renda per capita. Na região central, o padrão é distinto de todo o restante do sistema, mas as periferias não são indistintas, com as famílias de menor rendimento per capita se fixando em locais que combinam grande fragmentação, baixíssima integração com o restante do sistema e eixos 
Figura 3 - Mapas de análise de segmentos (variável choice)
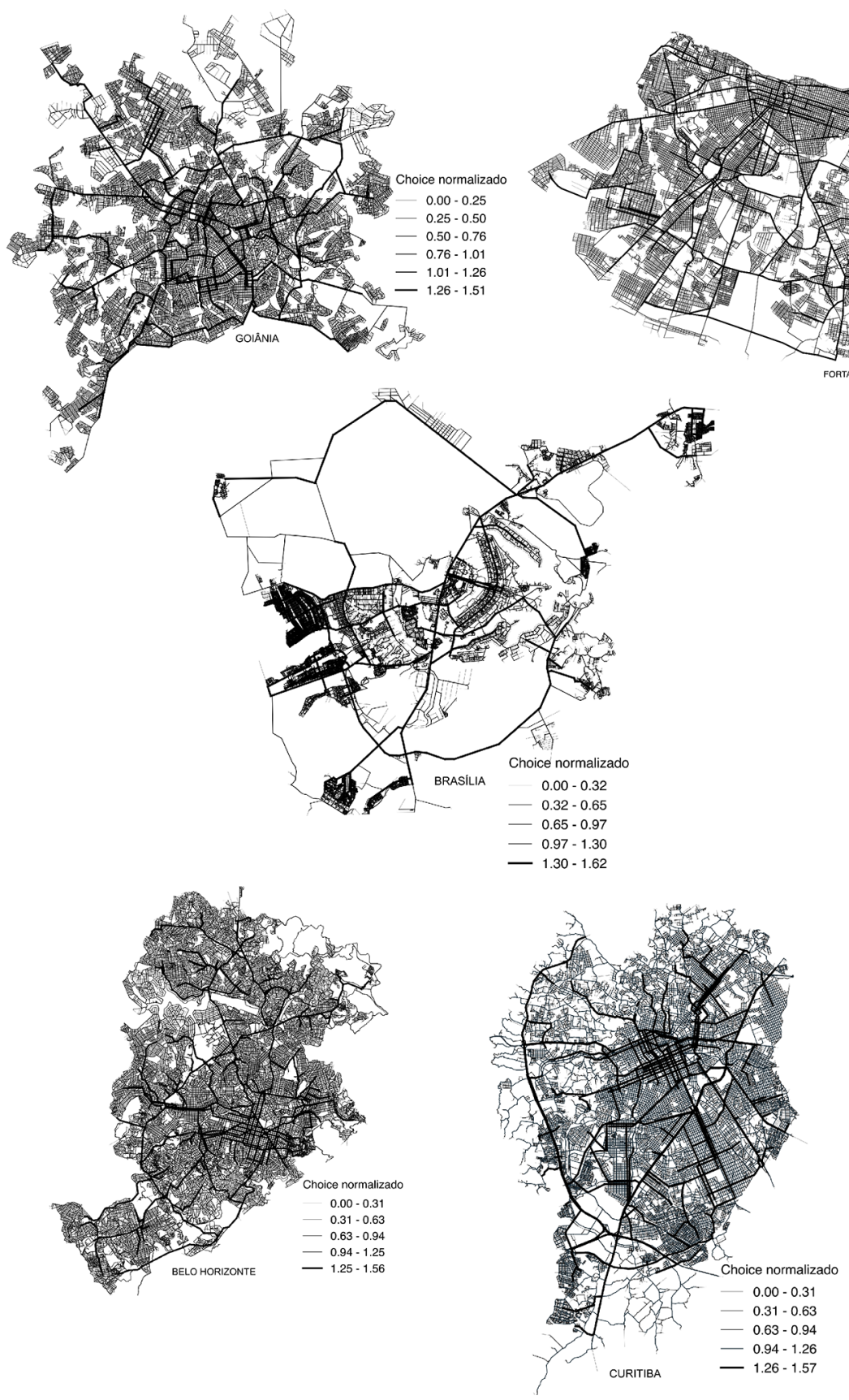

Fonte: elaboração própria, a partir dos dados do Censo IBGE (2010). 
globais de movimento mais desprovidos de conexões com outros eixos semelhantes do que nas demais regiões periféricas. Em segundo lugar, nota-se claramente que são as famílias de maior renda per capita que guardam a maior dependência espacial com a sua região de moradia do que os demais. É a relação entre acessibilidade local e global a marca distintiva de seus locais de moradia, já que a primeira permite a (re)produção social de seu modo de vida, ao otimizar os deslocamentos cotidianos de consumo típico das classes mais elevadas, e a segunda lhes assegura não só o acesso às vantagens da economia de escala da localização, é o traço distintivo que permite a apropriação maior da riqueza socialmente produzida em todo o sistema urbano.

Cabe ainda destacar que a dependência espacial que é percebida nos dois grupos antípodas de renda familiar cria um processo acentuado de segregação que parece não existir em grande parte das regiões das cidades estudadas. Assim, em volta dos centros expandidos, temos uma espécie de região invólucro de características intermediárias, ou seja, de dependência espacial não significativa, índices medianos de integração e a existência de um sistema com alguma densidade de vias globais de movimento que se interceptam em várias direções. Esse invólucro acaba por separar marcadamente os espaços da elite dos espaços das famílias mais pobres, assegurando certa distância social aos dois grupos.

\section{Conclusão}

A fim de retomar as questões surgidas ao longo do texto, algumas observações finais devem ser sublinhadas. Em primeiro lugar, grande parte das cidades tem regiões pobres propensas a serem circundadas por regiões igualmente não pobres, mas há ao menos duas regiões marcadamente segregadas e socialmente muito homogêneas.

Uma das regiões segregadas é o centro expandido, e ele nos parece ser o elemento-chave para compreendermos a relação entre segregação e morfologia urbana. As famílias mais pobres estão segregadas, mas essa segregação está menos associada à morfologia do que ao isolamento e à dependência espacial exacerbada do centro. Em um certo sentido, corroboramos as indicações de Medeiros, Guimarães e Castro (20015) e Reis (2000) de que é preciso estudar mais e melhor os mais ricos para compreendermos melhor o fenômeno da desigualdade socioeconômica no Brasil.

A segregação das famílias mais pobres é imposta no processo de produção social do espaço, ao passo que a segregação das famílias mais ricas é construída e autoimposta. Há uma relativa carência de estudo sobre as famílias mais ricas por claros motivos de escassez de dados. Entretanto também é evidente que a chave para melhor entendimento da dinâmica de apropriação dos recursos socialmente produzidos na cidade é compreender como os mais ricos (re)produzem seu espaço social.

As análises aqui reiteram as teses de Villaça (2001) sobre como a classe dominante, ao comandar a produção do espaço, controla os tempos de deslocamento por meio dos mecanismos de segregação, mas apresentam como a morfologia urbana é parte do processo de isolamento social na disputa das classes sociais pelo espaço enquanto consumidores dos recursos socialmente produzidos. 
Embora o País tenha conhecido períodos de inegáveis avanços socioeconômicos e de aumento da renda - inclusive dos mais pobres -, as nossas cidades continuam enfrentando uma intensa segregação dos mais pobres e dos mais ricos, mas apenas com o último grupo em plenas condições de se apropriar do aumento geral de riquezas. Isso se deve a estruturas espaciais muito fracas no que diz respeito à capacidade de grande contingente da população acessar o conjunto de recursos das cidades. Com isso, a desigualdade socioeconômica intensifica-se na medida em que uma parte considerável da população perde a disputa pelo direito à cidade e aos seus recursos e é sobrepenalizada por sua localização.

Na medida em que percebemos o número relativamente baixo de estudos urbanos no Brasil que se ocupam da relação entre o espaço construído e a morfologia da cidade, precisamos conhecer melhor essa relação de modo que os diagnósticos gerem, além do conhecimento, formas concretas para que gestores, formuladores de políticas públicas urbanas e construtores da cidade atuem no debate público sobre nossa renitente desigualdade e as maneiras de combatê-la.

Avançar na compreensão de como os ricos se beneficiam das políticas públicas de combate à desigualdade, de políticas de desenvolvimento urbano e do conjunto espacializado de recursos socialmente produzidos é tema que seguramente merece futuras investigações.

Em outras palavras, fica patente que, para compreender a desigualdade, não basta estudar os mais pobres, mas, antes, é preciso tratar os ricos como um tema prioritário na agenda das pesquisas sobre esse tema.

[I] https://orcid.org/0000-0001-6161-1129

Universidade Estadual de Goiás, Curso de Arquitetura e Urbanismo. Anápolis, GO/Brasil. patrick.zechin@gmail.com

\section{[II] https://orcid.org/0000-0002-3592-2246}

Universidade de Brasília, Faculdade de Arquitetura e Urbanismo, Departamento de Teoria e História da Arquitetura e do Urbanismo. Brasília, DF/Brasil. fredholanda44@gmail.com 


\section{Notas}

(1) Segundo Holanda (2002), na SE, um sistema especial é descrito menos em termos de sua ordem geométrica do que em termos de sua ordem topológica, com os atributos desta última sendo proximidade, circunstância, continuidade, descontinuidade, contiguidade, separação, integração, etc.

(2) A linha axial, como definida no âmbito da SE, é uma linha reta inscrita nos espaços convexos formadores do sistema viário da cidade, reproduzindo os percursos dentro dos limites dos espaços aberto públicos. A linha deve ser a mais longa possível (pois a linha longa define o acesso e a movimentação das pessoas), contínua (de maneira que passe por todos os espaços convexos desenhados no espaço), não podendo haver repetição de linhas em um mesmo espaço convexo, assim como a linha axial deve sempre estar conectada com outra.

(3) Nos estudos da SE, o que se entende por integração global é o grau de acessibilidade ou permeabilidade potencial que uma via - abstraída para a forma de sua representação linear possui. A integração dá-se por meio da quantidade de conexões existentes dentro do sistema urbano considerado, o que influi na potencialidade da linha como trajeto dentro da malha.

(4) "Dois-passos" ou "três-passos" referem-se às duas ou três linhas seguintes a uma linha principal, na qual há uma sequência continuada de uma linha para a próxima (considerando-se a passagem de uma linha para a seguinte como um "passo") e, por conseguinte, se duas linhas axiais se ligam à linha principal, dizemos que dois "passos" são necessários a partir de uma dada linha original.

\section{Referências}

ALMEIDA, C. M. (2009). "Introdução. O diálogo entre as dimensões real e virtual do urbano". In: ALMEIDA, C. M.; CÂMARA, G. e MONTEIRO, A. M. V. (orgs.). Geoinformação em urbanismo: cidade real $x$ cidade virtual. São Paulo, Oficina de Textos

ARRETCHE, M. (2018). Democracia e redução da desigualdade econômica no Brasil. A inclusão dos outsiders. Revista Brasileira de Ciências Sociais, v. 33, n. 96, pp 1-23.

BARROS, R. P. et al. (2011). "Sobre a evolução recente da pobreza e da desigualdade no Brasil". In: CASTRO, J. A. e VAZ, F.M. (orgs.). Situação Social Brasileira - Monitoramento das condições de vida 1. Brasília, Ipea.

DUNCAN, O. D. e DUNCAN, B. (1955). A methodological analysis of segregation indexes. American Sociological Review, n. 20, pp. 210-217.

HILLIER, B. (1996). Cities as movement economies. Urban Design International, v.1, n. 1, pp. 41-60.

(2000). Centrality as a process: account for attraction inequalities in deformed grids. Urban Design International, v. 3, n. 4, pp. 107-127.

(2009). Spatial Sustainability in cities. Organic Patterns and sustainable forms. In: 7th INTERNATIONAL SPACE SYNTAX SYMPOSIUM. Anais. Estocolmo, KTH, pp. K01:1-K01:20. 
HILLIER, B. e HANSON, J. (2003). The social logic os space. Londres, Cambridge Press.

HILLIER, B; PENN, A.; HANSON J. e XU, L. (1993). Natural movement; or configuration and attraction in urban pedestrian movement. Enviroment and Planning (B), v. 20, n.1, pp. 29-66. Londres.

HOLANDA, F. de. (2002). O espaço de exceção. Brasília, Editora Universidade de Brasília.

(2013). 10 mandamentos da arquitetura. Brasília, FRBH.

IBGE - Instituto Brasileiro de Geografia e Estatística (2010). Base de informações do Censo Demográfico 2010: Resultados do Universo por setor censitário. Disponível em: ftp://ftp.ibge.gov.br/Censos/ Censo_Demografico_2010/Resultados_do_Universo/Agregados_por_Setores_Censitarios/. Acesso em: 13 maio 2018.

MARICATO, E. (2003). Metrópole, legislação e desigualdade. Estudos Avançados, v. 17, n. 48, pp. 151-167.

MEDEIROS, M.; GUIMARÃES, P. H. e CASTRO, F. A. (2015). A estabilidade da desigualdade de renda no Brasil, 2006 a 2012: estimativa com dados do imposto de renda e pesquisa domiciliares. Ciência \& Saúde Coletiva, v. 20, n. 4, pp. 971-986.

REIS, E. P. (2000). Dossiê desigualdade: apresentação. Revista Brasileira de Ciências Sociais , v. 15, n. 42, pp. 73-75.

SABATINI, F. e SIERRALTA, C. (2006). “Medição da segregação residencial: meandros teóricos e metodológicos e especificidade latino-americana". In: CUNHA, J. M. P. (org.). Novas metrópoles paulistas: população, vulnerabilidade e segregação. Campinas, Nepo/Unicamp.

TURNER, A. (2000). Angular analysis: a method for the quantification os space. In: Centre for advanced spatial analysis - Working paper series.

UN-HABITAT (UNITED NATIONS HUMAN SETLEMENTS PROGRAM) (2012). State of the world's cities 2010/2011 - Bridging the urban divide. Londres, Earthscan.

VASCONCELOS, P. A. (2003). "Contribuições para o debate sobre processos e formas socioespaciais nas cidades". In: VASCONCELOS, P. de A.; CORRÊA, R. L e PINTAUDI, S. M. (orgs.). A cidade contemporânea - segregação espacial. São Paulo, Contexto.

VILLAÇA, F. (2001). Espaço intraurbano no Brasil. São Paulo, Studio Nobel.

Texto recebido em 19/out/2018

Texto aprovado em 6/nov/2018 